\title{
Art and Philosophy in Engineer's Training: Individual Pedagogical Experience
}

\author{
Aleksandr S. Borshchov \\ dept. of Philosophy \\ Yuri Gagarin State Technical \\ University of Saratov \\ Russia, Saratov \\ borshov@sstu.ru
}

\author{
Mariya A. Romashchenko \\ dept. of Philosophy \\ Yuri Gagarin State Technical \\ University of Saratov \\ Russia, Saratov \\ buk42@rambler.ru
}

\author{
Aleksandr A. Romashchenko \\ dept. of Philosophy \\ Yuri Gagarin State Technical \\ University of Saratov \\ Russia, Saratov \\ romaschenko.al@gmail.com
}

\author{
Natalya V. Dovgalenko \\ dept. of Philosophy \\ Yuri Gagarin State Technical \\ University of Saratov \\ Russia, Saratov \\ dovgal30@rambler.ru
}

\author{
Natalya N. Bontsevich \\ dept. of Media and Communication \\ Yuri Gagarin State Technical University \\ of Saratov \\ Russia, Saratov \\ zam_dekanavr@mail.ru
}

\begin{abstract}
The article describes the experience of using Visual Thinking Strategies in teaching philosophy for engineering students. On the example of training Bachelors of Engineers in Yuri Gagarin State Technical University of Saratov, the importance of using works of art for teaching philosophy and soft skills is analyzed. The authors make a hypothesis, that the explanation of abstract philosophical concepts on examples of works of painting is an effective tool of developing communication skills, empathy, tolerant thinking and visualization skills. All these soft skills are an important element of the engineer's training.
\end{abstract}

Keywords. Philosophy, soft skills, Visual Thinking Strategies, Thinking, Teaching, Art, Education, Interdisciplinary Studies, Visual art, Visual thinking.

\section{INTRODUCTION}

Modern engineering education is on the turn of significant changes. To a greater extent, it concerns the problem of developing not only engineer's special knowledge, but also soft skills [1]. Such changes affect the entire world community, including Russia.

The modern higher education institution is responsible for its graduates, because they are actively involved in economic and social development of the country and the region [2]. One of the main goals of training specialists, in particular engineers is the coordination of employer's requirements and results of training.

According to data of the All-Russian center of public opinion (https://wciom.ru/index.php?id=236\&uid=365), in Russia $55 \%$ of employers estimate the quality of training in Russian higher education as average and $28 \%$ give it a low rating. Only $5 \%$ of young professionals speak about poor quality education, and $58 \%$ of graduates evaluate their education and the acquired skills very high. Such data point differences of the employer's expectations and the real skills of young professionals. In addition, the system of modern Russian education inherits the Soviet logic of learning. In Soviet university the emphasis was placed on theoretical and fundamental knowledge. This has set a certain seal on Russian higher education. According to the Russian center for public opinion studies, a majority of young professionals $(56 \%)$, and the absolute majority of employers (91\%) admits a lack of practical skills of Russian universities graduates of 2016.

Similar situation can be observed in the countries of the European Union. F. Gobet in the article "Three views on Expertise: Philosophical Implications for Rationality, Knowledge, Intuition and Education" provides data from the 2010 - 2011 study, conducted in eight European countries. This study revealed a significant discrepancy between knowledge, that the managers of construction companies consider necessary, and knowledge and skills, which are needed virtually [3]. For example, if an employer in the construction industry has counted on technical knowledge, then in practice, skills going beyond theoretical knowledge had been needed. It became obvious, that the young specialist has lacked communicative skills, ability to solve conflicts, present his own opinion, use critical thinking and create projects.

Thus, it is obvious, that it is not enough to include only actual knowledge and hard skills, in accordance with the requirements of industries, in engineering education. They do not give a guarantee of professionalism. It is necessary to mould the student's emotional intellect, stimulate his creative thinking and ability to represent and visualize his ideas, projects and results of activity.

One of the most discussed topics about man and social sciences in modern sciences are the ways of soft skills forming. In the last 5 years, starting from 2013, in the Scopus database almost 2000 documents with the key word soft skills have been published. Most of them are posted in the last three years. But only 25 of 2000 have been written by Russian scientists. That is why this problem is especially urgent for Russian higher education today.

In the works of scientists, various methods of making soft skills are considered, which are applied to specific areas of 
specialist training [4]. Techniques based on science and art, and Visual Thinking Strategies interaction are of particular interest. Art becomes an effective tool that allows defining critical thinking and projecting skills in STEM (science, technology, engineering, mathematics) [5]. The literature describes many areas of learning, where Visual Thinking Strategies are used to make soft skills [6]. Particularly many studies are devoted to the use of Visual Thinking Strategies in the medical personnel training [7]. This technique is used for empathy development at nurses and future physicians [8]. Some interesting results have been obtained and specific methods of works of art analysis have been hammered out in this field of research [9]. The results of such studies and techniques can only be derived from the nursing area. Partially they can be applied in engineering education.

This article proposes the technique of using visual art works for shaping an emotional intelligence, critical and conceptual thinking. The purpose of this study is to establish techniques for using Visual Thinking Strategies to train an engineer and set up soft skills. Setting this goal assumes solving more specific tasks:

- first, testing techniques for using visual art as a creative practice in teaching critical thinking;

- second, using various forms of motivation for setting up soft skills at the bachelor engineers;

- third, assistance in study philosophy by bachelorsengineers.

The value of this research is that, in modern Russian higher education methods of making soft skills, as well as the use of regional socio-cultural resources, are being worked out. On the one hand, it allows establishing a constructive dialogue between the requirements of real employers and the specialists' results of training. On the other hand, such forms of training are mastered, which allows enabling an engineer as the creator of new meanings and concepts, expanding the area of application of engineering thinking.

\section{MATERIALS AND Methods}

In modern standards of Russian higher education, engineering curricula are designed in such a way, that the discipline "Philosophy" occupies an important place among the disciplines, responsible for forming general cultural codes of competences. In many respects, general cultural codes of competences correspond to what is called soft skills in English literature. Thus, teaching of philosophy is directly related to mastering students' critical thinking skills, communicative skills, and ability to form a comprehensive worldview.

Development of such skills in the context of "Philosophy" course in Y. Gagarin State Technical University of Saratov is promoted by a special technique of Visual Thinking Strategies. This article is devoted to it. A study have been conducted during the period of three years, between 2015 and 2017, among undergraduate students of the direction of training "Construction". Methodology of the project was based on the open interaction of the teacher, student, and student group as a whole. There were two variants of assignments.
In the first case, each student was instructed to explore any picture of the Renaissance to discover in it philosophical ideas of the period, in particular, anthropocentrism and humanism. He had to present his analysis to the student group in the form of a short speech. At first, a group discussion of the results of individual students took place outside a consideration of the historical context of an artwork. In the second stage of this work, Pico della Mirandola's "speech about human dignity" was connected to the visual image. Thus, a student compared two types of discourse: painting and text. During the work on this assignment, students were recommended to use the resource with digitized works of painting Google Art Project.

In the second case, students applied not to digital copies of paintings, but to the originals. The technique was worked out in Saratov State Art museum, named after A.N. Radishchev. Students were given the task to choose a picture, which reflects the philosophical concepts of "rationality", "ethics", "freedom", "value", "individualism" from the museum's collection. To find these abstract concepts in works of art, a student could choose different acting strategies, for example, independently examine the museum's space, contact the museum employee or change search parameters, which is to use other philosophical concepts. The only condition that could not be violated, is to leave the museum space. As a result of such searches, a student had to prepare a report and speak with it in the group.

The study involved three groups of bachelor students in the direction of "Construction". In 2015- the group of students in the number of 50, in 2016 - 39 students, and in 2017 - 41 students.

As a result of work with the project three assumptions were formulated:

1) visual works of art help students in mastering the skills of abstract thinking and basic methods of discourse analyzing;

2) search assignments develop communicative practices and stimulate project and creative activity;

3) use of paintings as a teaching material allows to compare technological and creative aspects of activity.

To confirm the basic hypothesis, a hermeneutical methodology was chosen. It allows interpreting students' individual experiences and discursive practices..

\section{RESULTS AND DISCUSSION}

Since Antiquity, it was clear that upbringing and education of man changes not only his individual intellectual features, but his personality, character and even the external image. This is a complete transformation. A new person gains a unique intellectual and emotional experience. Education, particularly, is directed on accumulation of such experience.

Proceeding from this, first of all, it is necessary to determine what kind of experience bachelor of modern engineer program should obtain. According to philosophical and pedagogical concepts of J. Dewey, experience is a person's contact with the world. Experience is individual. It is the synthesis of the subjective foundations of man and the 
environment with which he confronts. The experience is based on emotion, but it is impossible to define experience as only emotional. Dewey writes: «There are absorbing inquiries and speculations which a scientific man and philosopher will recall as "experiences" in the emphatic sense. In final import they are intellectual. But in their actual occurrence they were emotional as well; they were purposive and volitional. Yet the experience was not a sum of these different characters; they were lost in it as distinctive traits» $[10, \mathrm{p}$. 44]. In this sense, experience is syncretic. This experience can be improved. This is precisely the task, that education sets itself. Experience should be deepened and broadened. It should have a value and semantic context. J. Dewey himself describes it this way: «The action and its consequence must be joined in perception. This relationship is what gives meaning; to grasp it is the objective of all intelligence. The scope and content of the relations measure the significant content of an experience. A child's experience may be intense, but, because of lack of background from past experience, relations between undergoing and doing are slightly grasped, and the experience does not have great depth or breadth» $[10$, p. 50]. Thus, experience is carried out constantly as a binding of subjective experiences, emotions and environment.

Experience is not limited to the intellectual dimension. Educational environment, which is formed around student, influences not only his intellectual development [11]. In the original meaning, the term "aesthetics" meant sensual perception. In this sense, aesthetics cannot be excluded from intellectual experience. Moreover, the aesthetic experience, according to J. Dewey, is the most vivid.

Based on this, using works of art in education allows to link environment conditions and individual request of a person. This is especially important in training of an engineer. An engineer is a maker not only of technical objects, but of meanings and concepts. In modern digital culture, an engineer already deals not only with producing objects, but also with that, he should be able to properly create search queries in the information space. For this, an engineer needs to understand, that in the process of making a query or object, form becomes secondary. The main thing is meaning. The combination of philosophy and art makes it possible to synthesize cognitive and emotive aspects of learning, achieving an important outcome of education.

Philosophy gives an opportunity to develop an engineer's abstract thinking, skills of constructing senses, and art is a tool for expressing diverse meanings and cognitive prospects of such abstract concepts.

The method of combining a philosophical text and works of painting have been used in teaching philosophy of engineersbachelors of Yuri Gagarin State Technical University of Saratov. Students have analyzed digital copies of Renaissance paintings, using the Google Art Project information resource. Their task was to find in "symbolic texts" ideas of "humanism" and "anthropocentrism". As a result of analysis of students' interpretations of abstract concepts in the works of painting, a trouble has been discovered. At the first stage, students could not correctly set a semantic request to a picture. They could not connect an abstract idea and visual symbols. After an individual analysis of the work, each of the students made a short speech before the group, explaining the reasons, why he chose a particular work of art. As a result of the discussion, students were able to find that their errors in comparison of abstract ideas and visual images are similar in many respects. This resemblance was even stronger, when students were offered to comment the Pico della Mirandola's philosophical text «About Human Dignity». Understanding the text was more familiar to students. They already had such a cognitive experience. A teacher offered to compare the text with the selected works of art. This was the second stage of work. At this stage it was necessary to compare the text and the image.

This approach allowes a student to be a maker of discourse, which reveals the social, ideological, and cultural context. M. Foucault in his work «The Archaeology of Knowledge: And the Discourse on Language» calls painting a discourse [12]. It is a way of designation so peculiar, that it can go without words. Painting is a discursive practice, that has its own technological embodiment and results. This makes it possible to compare two discourses: a text and a visual image. This comparison-analysis complements Visual Thinking Strategies. This technique encourages a student to observe closely the meanings and images, and then verbalize their observations. This verbalization of observations after the joint analysis is defined already not in isolation, but in the context. A student interprets a text and image. He uses a tolerant approach, since he discovers multiple meanings and interpretations. At the same time, he gets emotional experience of perceiving not only visual image, but the very act of interpretation. Very often, during the discussion of the results of "anthropocentrism" and "humanism" concepts' interpretations in their visual embodiment, students have expressed contrary viewpoints. A clash of discursive practices has happened. Students have been trained to express their interpretation and take into account the interpretation of another student.

Thus, the first goal of the bachelor of engineering soft skills making has been succeeded. A student has been learning to "read" symbols, do a cognitive request, interpret not only an information, but also its context. The objectives of this technique are described in the table.

A second version of the assignment was based on that, after leaving a classroom students came to the museum space. Here it was necessary to use the experience of interpretations, which was acquired during the previous task. Students were invited to find works of art, which expressed one of the proposed philosophical concepts "rationality", "ethics", "freedom", "value", "individualism", in the exposition of Saratov State Art museum, named after A.N. Radischev. In case, the student did not find such a picture in the museum, he could offer an interpretation of another philosophical concept to choose from. This task requires two conditions. First, the student must know the definitions of the proposed concepts and associated philosophical theories. Second, based on his theoretical knowledge, he must clearly and precisely formulate his cognitive request, and possible options for its transformation.

During the second assignment many students have noted a difference in perception of digitized works of art and real paintings in the space of the museum exposition. In the latter 
case, the trainees recorded a higher level of emotional experience. Similar researches were conducted by American scientists and they came to similar conclusions [13].

In the museum space students have faced directly with the works of art of different epochs. They had emotional contact with them. Working with images on the Internet, students could discover art descriptions and interpretations. These interpretations shaped their prejudices, and imposed the imprint on their own interpretations. In the museum space students remained with a work of art one to one. Even in those cases, when a student asked for help from a museum employee, he had to accurately and clearly formulate his cognitive request, and determine the visual image he wanted to find.

The main purpose of the assignment in museum was to learn students to express concepts and abstract concepts, to formulate a search query so as to expand an area of semantic interpretations. It was the same activity as in the case of first assingment. But in the second case it was necessary to invert an assingment. In other words, it has become necessary for a student not only to find the meanings and values, but to express and visualize them.

After completing two job types, students noted, that they had acquired a unique emotional and intellectual experience. As a result of use of the described method of training, the student's ability to accept multiple interpretations and identify narrative structures through visual images and symbols has been shaped.

TABLE I. PURPOSE - ACTION MODEL

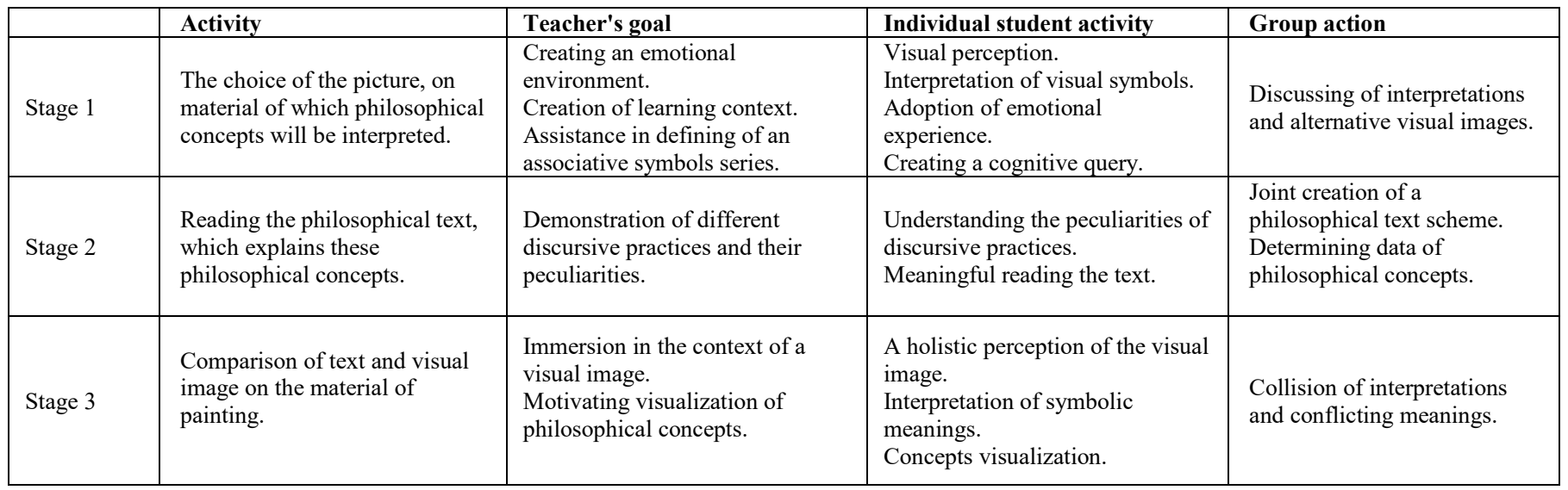

\section{REFERENCES}

[1] M. M Mohamad, M. H Yee, T. K Tee, M. Ibrahim Mukhtar and A. Ahmad, "Soft Skills in Pedagogical Practices with Different Curriculum for Engineering Education," in IOP Conference Series: Materials Science and Engineering, vol. 226, 2017.

[2] L. Small, K. Shacklock and T. Marchant, "Employability: a contemporary review for higher education stakeholders," in Journal of Vocational Education and Training, vol. 70, no. 1, pp. 148-166, February 2017.

[3] F. Gobet "Three Views on Expertise: Philosophical Implications for Rationality, Knowledge, Intuition and Education," in Journal of Philosophy of Education, vol. 51, no. 3, pp. 605-619, 2017.

[4] N. B. Kuru, "Visual culture in art teacher education: A Turkish case," in Procedia Social and Behavioral Sciences, vol. 2, issue2, pp. 609, February 2010.

[5] F. Lerner, "Visual-Spatial Art and Design Literacy as a Prelude to Aesthetic Growth," in International Journal of Art and Design Education, vol. 37, no. 1, pp. 65-73, 2018.

[6] P. Rumney, J. Buttress, and I. Kuksa, "Seeing, Doing, Writing: The Write Here Project," in SAGE Open, vol. 6, no. 1, February 2016.
[7] C. V. Elhammoumi and B. Kellam, "Art images in holistic nursing education," in Religions, vol. 8, no. 6, 2017.

[8] M. Moorman, D. Hensel, K. A. Decker and K. Busby, "Learning outcomes with visual thinking strategies in nursing education," in Nurse education today, vol. 51, pp. 127-129, 2017.

[9] M. E. Bentwich and P. Gilbey, "More than visual literacy: Art and the enhancement of tolerance for ambiguity and empathy," in BMC Medical Education, vol. 17, no. 1, 2017.

[10] J. Dewey, Art as Experience. The Later Works of John Dewey, 19251953. Volume 10: 1934, Edited by Jo Ann Boydston Carbondale and Edwardsville: Southern Illinois University Press. p. 44.

[11] I. Aguirre, "Beyond the understanding of visual culture: A pragmatist approach to aesthetic education imanol aguirre," in International Journal of Art and Design Education, vol. 23, no. 3, pp. 256-269, 2004.

[12] M. Foucault L'archéologie du savoir, Paris, Gallimard: "Bibliothèque des sciences humaines", 1969.

[13] D. Haw and J. Wagelie, "Studying artworks and their digital copies: Valuing the artist's aura," International Journal of Education Through Art, vol. $12, \quad$ pp. 2016. 